\title{
Sense of motion, senses of self: becoming a dancer
}

\author{
C.M.P. Potter (Potter, Caroline M. Parler) \\ Address: Institute of Social and Cultural Anthropology, University of Oxford, 51-53 \\ Banbury Road, Oxford OX2 6PE, United Kingdom \\ E-mail: caroline.potter@anthro.ox.ac.uk
}

\begin{abstract}
In spite of growing interest in the anthropology of the senses, the majority of literature has focused on the Euro-American 'classic five' senses of sight, sound, smell, taste, and touch at the expense of other equally viable senses such as heat, pain, and kinaesthesia. Through ethnographic description of a professional dance training programme in which I actively participated, I argue that developing a heightened sense of kinaesthesia (felt bodily movement) is a means of becoming a socialized into the professional dance community. Far from an isolated sense with discreet biological pathways, kinaesthesia requires parallel perception through multiple sensory modes including heat and touch. A focus on kinaesthesia therefore contributes to an understanding of the senses as a cohesive phenomenological complex that engenders an interconnected, bodily-grounded sense of cultural identity.
\end{abstract}

Key words: dance, kinaesthesia, heat, touch, body, training, senses

\section{Introduction: sensory anthropology}

A focus on the senses has received growing attention among anthropologists in the past two decades (Stoller 1989, Howes 1991, Ingold 2000, Geurts 2002). The anthropology of the senses, as David Howes defines this emergent field, is fundamentally concerned with "how the patterning of sense experience varies from one culture to the next in accordance with the meaning and emphasis attached to each of the modalities of perception" (1991:3). Howes maintains that the senses are both the shapers and bearers of culture (ibid:17), in that they not only influence social organization, understandings of self and cosmos, and modes of cultural expression (e.g. regulation of emotions, aesthetic performance) but also are elaborated or deemphasized by the same. Thus the relative importance of some modes of perception over others can be expected to vary across cultural settings and within the same culture over time.

Although some earlier writings on the senses as a rich avenue for the study of cultures and society did emerge (e.g. McLuhan 1962), variable 'sense ratios' went largely unrecognized by anthropologists until the mid-1980's. Stoller's (1989) account of 'learning how to hear' among the Songhay of Niger called attention to widespread anthropological ignorance of non-visual ways of knowing - for example through sound, touch, or kinaesthesia - and exposed the heavy visual bias that most ethnographers uncritically carried into the field. The anthropology of the senses is a means of deconstructing that visual bias and pursuing hitherto unexplored questions such as: Can human beings think through touch? Do multiple, sense-specific forms of 
intelligence exist? Is it possible for one to abandon one's primary sense ratio in order to understand the world through the sense ratio of other peoples?

Recent writers such as Geurts $(2002,2005)$ have built upon Ong's concept of the 'shifting sensorium' (1969, in Howes 1991) to describe peoples who experience the world through strikingly different modes of perception than the supposed visually dominant Euro-American way of being. As a starting point Geurts contends that the 'classic five' senses taught in Western schools (i.e. vision, sound, touch, taste, and smell) are inadequate for understanding the way in which Anlo-Ewe people of Ghana understand the world. She maintains that the Anlo-Ewe sensorium, or "pattern of relative importance and differential elaboration of the various senses" (2002:5), must also include senses of balance, kinaesthesia, and affects such as pleasure, pain, and other generalized 'feelings in the body'. Kinaesthesia, a sense of motion, is a particularly important sense for the Anlo-Ewe, as it not only represents a physical state of being (e.g. posture) but also indicates aspects of one's personality and moral sensibilities. A child, for instance, who walks lugulugu (meandering, swaying, moving in an aimless or distracted way) is sharply reprimanded by his/her mother, who fears that if the child is not corrected he or she will grow up to be lugulugu (directionless, lazy, drunken) as well (2002:76).

Perception through the 'classic five' senses also fails to fully convey the experience of British contemporary dance students during their full-time training. During fieldwork at a London-based school for professional dance (henceforth referred to as 'the School') ${ }^{i}$, I both observed and experienced the multiple sensory modes that inform the process of becoming a dancer. For the first ten months I actively participated in the daily training regime, while the following academic year was used to collect further data through structured questionnaires and informal interviews with students whose training was ongoing. Through this research I concluded that little-discussed senses of heat, kinaesthesia, and pain are prominent during contemporary dance training, and that two of the classic five senses - touch and sound - are given explicit attention to levels beyond those typically experienced in day-to-day life. In this article I will focus on kinaesthesia, a sense of movement, as a primary sensory mode through which students become socialized into the British professional dance community. By also discussing the overlapping sensory modes of heat and touch, I will argue that the senses should be understood as an intermeshed web of perceptory apparati that direct the body's total attention to its situation in the world, rather than as a set of discreet biological pathways that respond independently to physical stimuli.

Rather than examining a shifting sensorium across cultures or through historical eras, I am writing against the supposed visual hegemony of Euro-American cultures by exploring the emergence of a movement-framed sensorium among a subgroup defined by the bodily experience of their chosen occupation. I argue that not only is a shifted sensorium among this specific group possible, but that it in fact underpins the transformation of these dancers from students to professionals. A sense of motion, while excluded from the 'classic five' sensory classification, is highly elaborated among students of professional British contemporary dance. As I shall demonstrate below, attending with and to the body (to borrow Csordas's (1993) conception of "somatic modes of attention") through this often overlooked sensory mode is necessary for both identity with the professional dance community and subsequent professional success. First, however, my highly participatory methodology requires some explicit consideration. 


\section{Reflections as a dancing ethnographer: on participant experience}

As authors such as Ness (1992) and Sklar (2000) have attested, translation of movement research into written form presents inherent methodological challenges. While my methods might usually be called 'participant observation', the term 'participant experience' (Hsu 1999:15-17) is more apt. Beginning in September 2003, after successfully passing the School's highly competitive selection process that included an audition and physical examination, for ten months I actively undertook the training process that was my subject of study at a nationally respected contemporary dance school in London. My status as somewhat of an insider allowed me unique access to my field site, for although the administrators of my host institution were aware that my training was part of an academic project, I was nonetheless expected to gain entrance on my own merit as a dancer through the School's formal audition process. Thus, I was able to experience the movement-learning process and systematically observe it in my dancing peers within a well-established facility.

This level of participation brought some obvious advantages. It allowed me daily access to the community of study without emphasizing my status as a researcher, which would have undoubtedly changed the dynamics of specific social encounters; I predominantly gathered data through casual conversations and frequent observations rather than formalized surveys or interviews. Crucially, as a daily participant I had access to my own set of sensory experiences (including emotions) that stemmed from the training process. These I in turn related to other students, who similarly shared aspects of their own experiences. As institutionally-shaped sensory experience is both a product of dance training and the process by which successful training is achieved, access to the heightened perception of the senses within one's own moving body is necessary for a full understanding of contemporary dance training as a phenomenon in its own right. On this point I am in agreement with dance anthropologist Deidre Sklar, who maintains that

While it has been traditional practice to erase the researcher's body from the ethnographic text, 'subjective' bodily engagement is tacit in the process of trying to make sense of another's somatic knowledge. There is no other way to approach the felt dimensions of movement experience than through the researcher's own body (2000:71).

However, participant experience also entails certain disadvantages. My identity as a student at times resulted in restricted access to other groups within the School; I was not, for instance, privy to many discussions among teachers. Furthermore, in undertaking the highly repetitive daily regime of a student I was prone to the naturalization of my environment and may have overlooked data that might have been more apparent to a less indoctrinated observer. Finally, participation at this level brought with it physical exhaustion, which was often central to my experience and which may have reduced by ability to acquire more representational data. As a balance to some of these disadvantages, I also utilized some more formalized methodologies. At the end of my own participatory phase I distributed surveys among fellow one-year students. The following academic year I conducted interviews with second-year undergraduate students as a follow-up on themes that had emerged during my own training. I also distributed a School-wide survey focusing on sociological data, notions of an ideal body, and motivations for dance training.

During fieldwork I took a similar approach to Wikan (1990: xxv), in that I did not tape-record conversations and rarely took notes in the presence of others (in my 
case, only during the more formalized interviews held after my own training was over). Nor did I employ the use of a video camera, other than to purchase videos of performances recorded by the School that were readily available to all students. Thus, most of the events and conversations that I observed were recorded from memory some hours after they had occurred. While some direct quotations are taken from students' written responses to questionnaires, most representations of others' experiences are drawn from my own notes and therefore reflect context and repeated themes rather than highly specific utterances.

Of deeper concern to me was the ambiguity of my role as dancer/researcher and its effect on my relationships with other dance students. While I did not actively attempt to conceal my status as a researcher upon entering the School, concerns about acceptability and the relatively short time frame of the participatory phase of research made me reluctant to define myself as 'other'. Furthermore, my self-definition as a dancer was very real; I had twenty years' previous experience as a student of dance ${ }^{\mathrm{ii}}$, and I was genuinely looking forward to the training as a unique personal opportunity. The overlap of my status with that of other dance students facilitated the building of genuine relationships as we discussed the challenges, aspirations, and fears that we experienced during our shared learning process. My choice to emphasize, through participant experience, my identity as a dancer over that of a removed observer undoubtedly affected the rapport that I established with other dancers, and the material that emerged from our informal exchange captures the sweaty, exhilarating, repetitive, and sometimes painful process of learning to dance as an individually intense yet socially grounded experience.

\section{Kinaesthesia: a sense of motion}

A sense of motion is critically important for dancers, yet is almost never discussed by name. This is due in part to discrepancies in what to call it. A biomedically grounded term for a sense of motion is 'proprioception', coined by celebrated physiologist Charles Sherrington in 1906. Sherrington's research on reflexes of the nervous system built upon previously conceived notions of a 'muscle sense' by demonstrating that an animal's skilful movement involves concerted action of the muscles, spine, and brain. He described two fields of sensory receptor organs within the body: "Extero-ceptors" of the "surface field" included organs associated with the classic five senses (i.e. the skin, eyes, ears, and olfactory organs), while "Proprio-ceptors" lie in the "deep tissues" and work "largely through mechanical strains and alterations of pressure resulting from contractions and relaxations of muscles" (Sherrington 1907:471). While Sherrington recognized the importance of intention in generating human neuromuscular action (1947[1906]: 336), and while he made some strides towards demonstrating the role that other perceptory modes (particularly vision) play in one's sense of body positioning (1907:476), his "proprioception" does not adequately convey a sense of motion as experienced by dancers on a daily basisiii.

Because it pertains to the knowledge of one's body position in space, 'proprioception' has been employed by some dancers to mean "our sense of self" (D. Bull 2002) $)^{\text {iv }}$. Such a broad definition connotes much more to a sense of motion than a series of nerve impulses. Neuropsychologist Alexander Luria goes some way towards recognizing the coordinated interplay between the intentions of an embodied subject and the organized biological processing of sensory signals, referring to the skilful execution of movement as a "kinetic melody" (1970: 73). However, even this conception is a far cry from the immediate 'feeling in the body' (Geurts 2005) that 
contemporary dancers experience as they walk, balance, spin, stretch, crouch, jump, curve, fall, bend, toss the limbs into space, run, shake, remain still, crawl, roll, or lift someone during daily training. In spite of a surge of anthropological interest in the body since Blacking's seminal work (1977), including a growing focus on the moving body (Reed 1998, Farnell 1999), anthropologists still struggle to describe culturallysituated ways of moving in terms that capture the energy, sweatiness, ease, pain, and other 'feelings in the body'. In discussing the emergence of a 'kinesthetic trajectory' in ethnographic dance studies since the early 1990's, Sklar indicates the varied and inconsistent terminology that permeates what she refers to as the "somatic dimensions of movement knowledge": "embodied knowledge, proprioception, somatesthesia, kinesthetic ambiance, kinesthetic empathy, and synaesthesia" (2000:70).

In describing a sense of motion grounded in the daily experiences of the lived body, I will employ the term 'kinaesthesia', which I define as: a dynamic sense of constantly shifting one's body in space and time in order to achieve a desired end. Although at times used interchangeably with 'proprioception', kinaesthesia carries less emphasis on a specifically biomedical understanding of movement and instead conveys a more general ability to feel the motion of one's own body and to adjust it in culturally preferred ways. Sklar implicitly makes a similar distinction, referring to kinaesthesia as "felt experience" and proprioception as "the reception of stimuli produced within one's own body, especially as movement" (2000:72).

For British-trained contemporary dancers, kinaesthesia may be understood as a heightened appreciation for one's relationship with gravity ${ }^{\mathrm{v}}$. This sense of motion normally operates as background "tacit knowledge", but in the context of dance training it often shifts into the realm of "focal knowledge" that is consciously assessed (to draw on terms used by Parviainen (2002: 17)). Phrases employed by contemporary dance instructors such as 'melt into the floor', 'feel the weight of the head', and 'anchor the [heavy] pelvis into the ground' prompted students to bring the body's relationship with gravity to explicit attention. A focal point for this attention was 'the centre', a conceptual area of the torso where the dancing body's 'connected' movements are meant to originate. In classical ballet the centre is indicated in the region of the rib cage and is used for 'pulling up', the action of lifting the upper torso away from the pelvis to give the appearance of lightness in the upper body, creating an ethereal quality to the movement. In contrast, contemporary dancers tend to indicate a lower position of the centre, in the region of the pelvis, which translates to movement qualities of 'weight' and 'groundedness'. Even when contemporary dancers leap into the air (by sending their centres there), gravity is always working against them to pull them back down. Sometimes the 'groundedness' becomes so pronounced that the contemporary dancer's body sits, squats, rolls, or falls quickly from an upright stance to the floor. Through training she ${ }^{\mathrm{vi}}$ learns to feel her dancing body's relationship to gravity at a number of levels - from active resistance when fully upright to total submission when her body weight is released to the ground.

A contemporary dancer's highly developed sense of motion also entails the ability to distinguish between, and ultimately control, feelings of tension and relaxation ('release') within the body. In choreological terms, this is an understanding of movement 'flow' - an aspect of movement effort, as conceived by movement analysis pioneer Rudolf von Laban, that occurs along a polar axis between 'free' and 'bounded' action (Laban and Lawrence 1974). An implicit goal of training, the ability to control movement flow was emphasized in the course aims of technique classes, including "achieving and maintaining efficient alignment" and "the use of energy appropriate to the movement" (Programme Handbook 2003:9-10). "Efficient 
alignment" referred to positioning the body along a vertical 'plum line' (in line with the field of gravity) so as to minimize muscular strain. Students were advised to 'stack' body parts vertically, so that parts closer to the ground such as the feet and legs would easily support the pelvis, which in turn would support the torso and head. A model skeleton - attached to a pole by its skull so that its spine, pelvis, and legs hung vertically with no effort - was used to illustrate to dance students that while enough tension was needed to maintain the image of length in the legs and spine, an efficient alignment would minimize the tension required to move upright through space. In terms of "energy appropriate to the movement", students were asked to consider the minimum amount of effort needed to perform specific movements with control, while still maintaining a feeling of 'easiness' in the body.

For many, achieving this 'efficient alignment' and 'easiness' as the body moved through inverted positions such as handstands was particularly challenging. During one improvisation class, the teacher gave us a seemingly simple task: travel the length of the room, alternating contact with the floor between hands and feet. On our first attempt, many of us were extremely awkward when weight shifted onto the hands; we swung our legs along the ground as quickly as we could, maintaining a crouched and tense posture. A few people utilized cartwheels, and a very few were able to suspend themselves upside-down for a few moments before the feet glided in smooth arcs back to the ground - rather than crashed, as many feet were doing. Our teacher participated in the exercise, occasionally becoming still on his hands and gazing lazily at us from his inverted position. His legs and torso exuded calmness; the only movement for several moments might be the turning of his head as he scanned the line of faces among his observing students.

On subsequent attempts across the floor he asked us to shift our focus away from 'being on the hands' to 'sending the tail [pelvis] above the head'. This instruction resulted in more expansive and controlled movements from the majority of students. Feet lifted higher off the ground and the distances between skull and pelvis gradually increased, resulting in 'longer spines' that appeared more 'efficiently aligned'. For the final phase of the exercise we travelled across the floor in pairs, with one person continuing the movement while the partner followed closely behind.

During the tail-over-head moments, the partner stepped in to hold the traveller's body in an upside-down position, affording the inverted body several seconds to appreciate what a good balance between tension and relaxation during this movement might feel like. By the end of the class the movement felt easier to me, with my partner exerting little force to keep me upside-down. Other students commented that their bodies were feeling 'lighter' with each successive attempt of the handstand. Kinaesthesia was thus not only utilized for the perception of bodily actions - standing on balance or falling, initiating a new movement or remaining still, suspending the body's weight into the air or releasing it towards the ground - but also as a means of perceiving progress and bodily change.

During training the kinaesthetic ability to perceive and control bodily feelings extended beyond the manipulation of one's biological physicality; it also applied to the management of emotions. Emotional tension, linked to feelings of alienation and bodily vulnerability, could stymie a dance student's motivation during training and potentially prevent her from completing it. As an example, on one occasion a female classmate in her mid-twenties, whom I judged to be one of the most technically skilled dancers of the group, unexpectedly started crying at the end of one class and chose to observe rather than participate in the next. She claimed that she was not 
injured or in pain, but immediately after the class she expressed to me a sense of disorientation:

I am feeling these changes inside of my body, and the changes are good... but I don't have the same control over my body and can't do things I used to be able to do.

She was acutely aware of emotional tension stemming from her training, which she was struggling to manage:

When I was studying at university I worked hard and exams were difficult, but when I finished for the day I could leave it. But here there are feelings...I can't leave them. I think about dance when I go home, and if I'm sad about dance then I can't leave it...I take it home and think about it all night.

Thus the desired 'freedom of movement' also entailed an emotional freedom to pursue the rigorous training regime whole-heartedly. That emotion management is so strongly intertwined with the self-disciplining of the simultaneously subjective and objectified body is not surprising in lieu of Milton and Svašek's contention that "emotional acts are simultaneously bodily movements, symbolic vehicles that reproduce and affect social relations, and practices that reveal the effects of power" (2005:13).

Kinaesthesia as an internally perceived sense renders it difficult to describe at the interpersonal and social levels. On the one hand the ability to perceive the felt experience of movement within one's body seems a universal human capacity, but on the other hand the anthropologist's analysis of another's sense of motion is filtered through her own non-kinaesthetic senses, chiefly vision and sound. Beyond one's personal attempt to experience the movements first hand, data is gathered via visual observation and dialogue with other moving persons. Dance students recognized this tension between internally- and externally-directed ways of knowing the human body; many told me towards the completion of their course that while they were uncertain if they 'looked' much different, they 'felt' significant changes within their bodies in comparison to the beginning of training. Teachers also recognized this inherent tension between directing attention inwards, towards the workings of one's own body, and outwards, towards an audience with whom one attempts to relate. On an end-ofterm evaluation I received the following comments:

Keep working to balance the internal connection with the external (desire to 'perform'). Therefore, the 'out there' moments are balanced by a clear sense of the self at the centre of the moment, and at the centre of a process of decision-making - about the how, where, and when of each movement.

I interpreted that the "internal connection" which led to "a clear sense of self at the centre of the moment" was a highly elaborated sense of kinaesthesia, an inwardly directed perceptory mode that was the ultimate goal of dance training. Although an audience would chiefly rely on the dancer's "external connection", conveyed largely through vision and sound, to evaluate the movements performed on stage, the dancer herself relied on different sensibilities - on knowing where she was in space, whether or not she was performing her intended movements well, and what 
qualities of movement she wanted to project. For the dancer, kinaesthesia is a crucial sense that frames the shaping of all other sensory modes, interconnecting one moving body to another and strongly contributing to dance students' identity with other selves who similarly prioritize a sense of movement.

\section{Heat: a sense of energy and life force}

The development of a heightened sense of motion is strongly connected to the concerted employment of other sensory modes. I will now describe another sense that falls outside of the five-sense model and that is intrinsically linked to a sense of motion.

Heat, a sense of energy, has received only scant attention in the anthropological literature. It is considered by some to be a specialized sense of touch that operates through thermal receptors in the skin (Geurts 2002:8), but I consider heat and touch to be distinct perceptory modes both in terms of what is physically experienced by the body and in the variable levels of significance that these two senses carry. As I shall elaborate below, touch is a proximal sense concerned with the immediate contact of a body to an external object through the skin. Heat, however, is perceived both within the human body and at its boundaries, where it meets and merges with the external world. Due to its trans-boundary capacity, I consider heat to be similar in experience to smell. While touch largely operates within the realm of human affairs, the perception of heat creates connections not only between body and environment, but also between humans and cosmos and between life and death.

Classen (1993) provides an astute account of the Tzotzil, Maya descendents living in the Chiapas highlands of Mexico, in order to demonstrate a sensorium dominated by heat. According to Classen, for the Tzotzil heat is the driving force of the universe, ordering both time and space (1993:122). Heat is equated with power, such that the gods (especially the sun) possess more heat than humans, while men possess more heat than women (ibid:124). Humans accumulate heat throughout their lives, most notably during significant life events such as being baptized, marrying, or becoming a shaman. Depending on its particular manifestations, an episode of illness is considered to be either a shortage or overabundance of heat, with treatment consisting of symbolically hot medicines and foods accompanied by a sweat bath taken in the morning (the hottest part of the day, connected with the rising sun) in the case of heat shortage or the administration of cold medicines and foods and a cooling bath in the case of overheating. Although heat is strongly connected to other sensory modes - the visual display at ritual meals, for instance, is arranged according to the perceived heat capacity of various persons and objects at the table-Classen is right to call attention to the perception of heat energy as a sense in its own right.

Although it is not formally discussed as a separate sense in the British context, heat is a crucial sense of energy that is discussed and experienced informally among dancers. 'Warming-up', or increasing the body's internal temperature, is considered a necessity for effective performance and improved bodily learning during training. Indeed, students were advised to warm themselves up for up to thirty minutes before starting the first class of the day, and although only a small portion actually did so, most students at least performed a few 'energizing' exercises (e.g. running around the room) or gentle movements such as stretching in the ten minutes before class. During the warm-up, the temperature of the skin increases and sweat begins to coat the body as internal heat is released into the surrounding air. Muscles begin to feel more mobile, and deeper stretching is attempted. Regardless of whether or not students had already warmed themselves up, teachers led a warm-up as the first portion of any 
dance class at the School. Energetic choreographic sequences - those that are very fast, for example, or include high-impact jumps - are only taught in the later stages of class, when the entire studio buzzes with rising heat. For a dancer, a sense of heat is a sense of internal energy and bodily readiness.

With its connection to blood and life force, dancers also associated heat with healing, while 'getting too cold' during classes or rehearsals was cited as a possible cause of injury; these associations with health are in line with body heat as it was understood in pre-modern Europe, based on the writings of Galen. 'Hot and cold' was the School therapist's recommended remedy for most minor injuries. Its underlying principle linked the flow of heat with the flow of blood, which was in turn expected to cause positive physiological changes. The therapy involved applying a heat source, such as an electric heating pad, to an injured area for two minutes before alternating to a cold source, such as an ice pack, for a further two minutes. Alternation between hot and cold continued for at least twenty minutes, and an injured dancer was encouraged to repeat the procedure at least three times a day. Heat was thought to cause blood vessels to expand, bringing blood to the injured area. Cooling in turn caused the blood vessels to contract and reduced blood flow. The alternation between hot and cold, between expanding and contracting blood vessels, was used to create a 'pumping' mechanism similar to the beating of the heart. This 'pumping' facilitated an internal movement of the body's life force, drawing away damaged matter and replacing it with renewed energy.

Perhaps most importantly, heat in the studio was a means of sensing the life force of others. When students entered a studio for their second class of the day, they were often hit by a palpable, dense heat that indicated the recent occupation of the space by others. Shared heat in the dance studio is comparable to the "red-hot sociality" (honghuo) that Chau described in rural Chinese temple festivals (2006:148). Red (hong), the colour of happiness, good fortune, and vibrancy, dominates during the temple festivals. Fire (hиo), indicating heat, popularity, and excitement, is an apt descriptor for the dense crowds of people who gather to play games, drink, pray, observe or participate in theatrical performances, eat, burn incense, and listen to the interpretation of divination poems. Honghuo is a social heat, generated by the gathering of living bodies and heightened through an explosion of sensory activity. For Chinese peasants, it gives rise to magical efficacy (ling) of religious events as well as to an energized, joyful household (ibid:153).

For British dancers, a heated sociality gives rise to the accomplishment of new physical feats and an increase in creative energy. A studio is socially heated both figuratively and literally; while the increased motion of bodies moving together gives rise to heightened exertion and excitement among a group of students, heat is also perceived tangibly through changes in room temperature and the emergence of sweat. A sense of heat thus begins within the individual body but quickly transfers into the social realm. Its conception is physiologically grounded, stemming from the flow of blood and the beating of the heart. Yet as acting body-subjects dancers willingly control the production of heat, choosing how much and in what capacity they 'warm up' and 'cool down'. Heat is also experienced in an objective capacity, as its perception leads to the recognition of other bodies and external heat sources in space. Inside the studio hot, odour-emitting bodies are allowed and even celebrated, but as students leave for the day they encourage this heat (and associated smells) to dissipate as the motion of their bodies simultaneously decreases. Many take a shower, change into cool and dry clothes, and/or cover themselves with perfumes or deodorants before stepping onto a crowded bus or train, where heat, odour, and motion are 
actively discouraged. Just as 'warming up' prepares one to enter the studio or stage, 'cooling down' prepares one to re-enter the non-dancing world.

\section{Touch: a sense of others' movement}

Far from hindering perception through the 'classic five' sensory modes, perception via kinaesthesia and heat in fact augments the dancing body's engagement with the world through vision, sound, smell, taste, and touch. I shall now illustrate how a heightened sense of kinaesthesia contributes to a reinterpreted sense of touch among British contemporary dancers.

Touch and taste are what I deem boundary sensory modes (in contrast to the trans-boundary modes of heat and smell); they are the senses that bring explicit attention to the body's boundaries, and their social shaping defines what external objects may be contacted and consumed by individual bodies within a cultural group. Both require the selective engagement of the physical body with objects in the world, with their only significant difference being the site of bodily contact (i.e. either the skin or the mouth). Perception through these boundary senses involves an immediacy of experience, a short-term bodily response to the contacted objects - which may, of course, be other bodies. Drawing on an historical account of Chinese pulse diagnostics, Hsu invokes the work of Merleau-Ponty (1962[1945]) and Mazis's discussion of the caress (1979) to argue that touch is unique from other modes of perception in that "whatever you touch, touches you too" (2000:252), leading to a "partial melding of subject and object" (ibid:264). Socially laden expectations about the nature of that experience continually influence decisions regarding future contact with those touched objects - whether repeated contact with particular substances or persons will be sought, avoided, or outright prohibited. As such touch and taste are highly socialized senses. The sharing of objects of touch/taste fosters identity with one's own cultural group, while the prohibition of eating or touching in certain ways designates shared social values among one group while simultaneously distinguishing it from other groups who do engage in the prohibited actions.

Touch is highly elaborated among contemporary dancers, particularly those performing within contact improvisation (described in sensuous detail by Novack 1990) and/or physical theatre. Contact improvisation emerged in the USA during the early 1970's, when less formalized, more 'pedestrian' movement forms were gaining credence among some professional dancers. Based on partnering work, its basic premise is that movements are generated through the shifting physical contact of one body with another. Contact may range from a gentle touch to the full supporting of a partner's weight (i.e. one partner lifts the other off the ground). In describing this experimental movement form, dancer and scholar Cynthia Jean Cohen Bull (a.k.a. Novack) writes, "The dancers are supposed to be absorbed in experiencing the movement and sensing (largely through touch) the experience of their partners... abandoning self-control in favor of mutual trust and interaction" (2001:406).

During my first contact improvisation session I was paired with a 19-year-old English female who had predominantly studied ballet prior to entering the School. She stated early on that she had opted for contemporary dance training in order to 'loosen up', referring not only to her movement style but also to a 'letting go' of some previous stresses that she had encountered during ballet training. We began the session with an exercise that was supposed to 'bring attention into the body', a phrase repeatedly used by the teacher. One person lay on her front with eyes closed while the partner placed her hands on various places on the back - between the shoulder blades, along the sides of the ribs, at the sacrum, etc. As the partner did so, the person lying 
down was asked to 'send the breath' and 'send the attention' to the areas being touched. The active partner then began to gently add more pressure and direction in the placing of the hands, 'encouraging' the still partner to move in response to the touch. Movement usually began as a small side-to-side rocking motion, but eventually the partner with eyes closed was moving more freely. She might roll over, sit up, or temporarily stand as the other partner alternated between 'following' her movement and actively using touch to 'encourage' movement in another direction. Ultimately contact with just the hand gave way to contact with other parts of the body - back to back, arm to leg, stomach to hip, etc. Any connection was permissible, as long as the contact was maintained and a certain degree of politeness (i.e. avoiding putting pressure on the face, knees, and other sensitive areas) was upheld.

By the end of the session both partners had experienced this type of movement with eyes opened and closed. At times we ended up rolling on top of each other, and I was often conscious of trying not to apply my full weight to my partner's head, hands, knees, and breasts. Equally, I was hyper-aware of the movements of my own body. Attention rapidly shifted between senses of kinaesthesia and touch; in one instance I acutely perceived the contact of my face to my partner's, while in the next I felt myself falling as we tried to maintain back-to-back contact. The constant motion of both partners led to frequently shifting points of physical contact, such that throughout the exercise it became difficult to distinguish between sensations of touch versus kinaesthesia. At the conclusion of the session everyone looked a mess, with clothes twisted and hair dishevelled. A number of students commented that their bodies felt warmed up and limber in spite of the fact that they generally felt drowsy, as if coming out of a light sleep. As we were leaving my young female partner commented to me, "that's the closest I've ever been to another woman before." While I will not elaborate on the gendered aspects of British contemporary dance training here, this comment indicates that ways of touching as permitted within the School varied markedly from conventions of touch (with their significant implications for the performative construction of gendered identity) that were followed outside of the studio. In actively attending to a sense of motion, dance students also reconfigured their sense of touch - a collective reshaping of multiple sensory modes that is suggestive of the senses as highly interconnected.

As the above example indicates, the senses are not experienced as separable biomechanical pathways in which particular physical stimuli give rise to specific bodily responses. Instead the senses are collectively perceived as a cohesive phenomenological complex that gives rise to a total experience of the body in the world. In describing three senses that receive heightened attention among Britishtrained contemporary dancers, my objective is not to prioritize these sensory modes at the expense of others, but rather to clarify which aspects of the sensory complex are most readily perceived in certain moments among a particular cultural group. I have highlighted touch as a separate sense here in order to illustrate that it is more highly elaborated by London-based students of professional contemporary dance than by the general London public. However, as I shall further demonstrate below, the elaboration of one or more sensory modes does not necessarily suppose the suppression of others.

\section{Conclusions: cultural identity as a dancer via a shifted sensorium}

After describing three prominent sensory modes that are employed by contemporary dancers during professional training, I now turn to the task of depicting their collective sensorium as distinct from that of non-dancers. Heightened attention to the kinaesthetic sense is strongly engendered during dance training, and a steady 
awareness of this perceptory mode is a characteristic which sets the British contemporary dance community apart from other British groups who do not actively attend to a sense of motion on a daily basis. The internalizing nature of kinaesthesia makes it difficult to analyze within the context of fieldwork, yet it has the advantages of being constantly perceptible (in contrast to pain, another internalizing sense that may appear to come and go without warning) and highly interconnected to all other sensory modes. As described above, a sense of motion is intrinsically tied to a sense of heat. Kinetic energy, connected to warmth and the flow of fluids (e.g. blood, odours), indicates vitality, while stillness is associated with coldness and may designate illness, injury, or the absence of life force. Similarly, for professionally trained dancers a sense of touch operates in harmony with a sense of motion: contact of the hands leads to the sharing of weight as two dancers lean away from each other in a counterbalance, or contact within the pelvic region leads to one partner easily supporting the full weight of another in a lift. In concert with these and other complementary senses, a heightened sense of motion is explicitly developed during training and is considered necessary for professional success.

In his description of capoeira, a Brazilian martial art / dance form, Downey argues for a sense of bodily motion that incorporates, and yet moves beyond, a biologically informed notion of 'muscle memory'. He writes,

When a capoeirista, or capoeira practitioner, grows accomplished in the bananeira [a form of handstand], he or she is not learning a reified movement, like a motor programme or automatic reflex. The skill alters the sensitivity of practitioners' central nervous systems, their behavioural repertoires, their sensory information flows and even their bodies' gross structure.

(2005:57)

In distinguishing kinaesthesia from proprioception, I have endeavoured to portray a dancer's sense of motion as one that is based in the physiology of the biological body, and yet honed and directed through active attention to feelings in the body, including emotions. I therefore understand 'kinaesthesia' in much the same way that Downey (2005:60) presents a sense of 'balance' - as an "entire perceptual system" that encompasses not only the workings of specific sense organs (such as proprioceptors in the muscles and semicircular canals in the inner ear), but also the integration of the moving body's intentions and information from other sensory channels. With specific reference to contemporary dancers who have undergone professional training in Britain, I contend that this socially constituted sense of motion is the prominent sense that frames the entire perceptory system of the dancer. Downey's argument that "Cultural distinctiveness inheres not only in behavioural patterns and cognitive 'contents' - symbols, signs, representations - but also in the way that physical practices shape the unfolding development of a skilled body" (2005:57) lends support for viewing dancers who train together as a distinct cultural grouping.

Upon delineating the emphasis placed on the sensory modes of kinaesthesia, heat, and touch by British-trained professional contemporary dancers, I now wish to call -into question the supposed "hegemony which sight has for so long exercised over our own culture's social, intellectual, and aesthetic life” (Howes 1991:4). Undoubtedly, the vast array of images that permeate British consciousness through photographs, film, and the printed word do give authority to the notion that 'seeing is believing' and imply that vision is the dominant sensory mode through which peoples of Euro-American cultures make sense of the world. Furthermore, the reproducibility 
of a visual image is commensurate with a British cultural history informed by the pursuit of scientific truth. But for British students of professional contemporary dance, a lifeworld framed solely by the five-sense model of perception, with an overwhelming emphasis on vision, makes no sense. The kinaesthetic mode most strongly organizes daily experience for this cultural group, and it is through attention to the internalized sensations of bodily movement that selective attention via other perceptory modes - including heat, touch, vision and sound - is steadily shaped. Certainly dance students gather information about the world through images and written text. What defines them as a group, however, is the daily struggle to understand why their physical bodies move in certain ways and how they might learn to master other ways of moving that at present feel awkward or unfamiliar.

As an anthropologist seeking to understand that struggle, my own body served as a resource for exploring ways in which "contorting and moulding the body shapes, affects and influences the mind" (Skinner 2005: vi). In line with Skinner's assertion that "the role of embodiment should be treated as a not insignificant area of concern and attention in teaching and learning, particularly in anthropology" (ibid.), this article is a call for expansion of "participant experience" (Hsu 1999:15-17) within the field of sensory anthropology. This method opens new avenues for probing the transmission of culturally-situated bodily knowledge, a process that Ingold calls an "education of attention" (2001:139). Engagement of the anthropologist's body in the research process can yield new theoretical insights. For example, only by sweating through the daily training did I begin to understand what Sklar refers to as "the doubled act of moving and feeling oneself moving" (2000:72). For professionally trained dancers, and perhaps for other groups who emphasize a sense of motion, that "doubled act" creates "an ultimate intimacy, a doing while being with oneself" (ibid.) that is central to their construction of self and identity. This 'doubleness' resonates with a series of pairings offered by other authors to describe a sense of movement that is simultaneously generated (often unconsciously) within the body and subject to reflection by the body: the lived body ("Leib") and the physical body ("Körper") (Husserl 1960), "tacit" and "focal" bodily knowledge (Parviainen 2002), the "sensible" and "the intelligible" (C. Bull 1997), "attending with" and "attending to" the body (Csordas 1993), "structured structures predisposed to function as structuring structures" (Bourdieu 1977), "body-of-ideas" and the body as a subject of analysis (Foster 1997), the observing and observed dimensions of the "present-absent body" (Leder 1990), and "body-subject" and "body-object" (Potter 2007, from MerleauPonty 1962 [1945]). This doubleness of bodily experience should continue to be explored through highly participatory fieldwork methods.

Based in part on the data that I have presented above, I believe that there is evidence to support the argument that the sensorium varies across cultural groups and is reproduced through a process that Lave and Wenger (1995: 56) call "situated learning" - a bodily apprenticeship through which novices eventually become competent masters as they are socialized into a community of knowing practitioners. Ong thought of the sensorium as a culture's "productive specialization" of the use of the human sensory apparatus (1969, in Howes 1991:28), while thirty years later Geurts deemed it the "pattern of relative importance and differential elaboration of the various senses", which included kinaesthesia and balance (2002:5). Stoller (1989), Classen (1993), and Friedson (1996), among others, have described sensory orientation to the world in terms of perceived sounds, smells, heat, tastes, and motion that are elaborated beyond the levels these authors experienced in their 'visually dominant' home cultures. These and other 'sensory' authors have tended to highlight 
the use of one or more non-visual sensory modes in order to contrast it with the 'visual hegemony' through which western cultures supposedly know the world. These writings are valuable for alerting Euro-American writers to the pitfalls of focusing solely on visual representations of culture and ignoring other ways in which the peoples of study make sense of their environment and their place in it. However, further undertaking of experiential, body-centred ethnography is needed in order to elucidate the patterned use of multiple, overlapping sensory modes in specific cultural contexts.

\section{Acknowledgements}

I am heavily indebted to the many talented and inspirational people that I met at my host institution, London Contemporary Dance School. I am grateful to its director and administrative staff for enabling the opportunity for such unique research. The teachers who were there from September 2003 to July 2005 have my continued respect and gratitude. Most of all, I offer my thanks to the students, who danced through the daily demands of training with amazing energy and dedication. I wish them the very best for personal and professional success.

I thank my former supervisor, Dr Elisabeth Hsu, for her continuous feedback on drafts of this article and on the doctoral research that informed it. I am also grateful to the three anonymous reviewers for their detailed and constructive comments.

This material is based upon work generously supported by a United States National Science Foundation Graduate Research Fellowship and a Rhodes Scholarship. Any opinions, findings, conclusions, or recommendations expressed in this publication are those of the author and do not necessarily reflect the views of either the National Science Foundation or the Rhodes Trust.

\section{Bibliography}

Blacking, John. 1977. The Anthropology of the Body. London: Academic Press. 436 pp.

Blakey, Paul. 1994. Stretching Without Pain. Stafford: Bibliotek Books. 80 pp.

Bourdieu, Pierre. 1977 [1972]. Outline of a Theory of Practice. Trans. Richard Nice. Cambridge: Cambridge University Press. 224 pp.

Bull, Cynthia Jean Cohen. 1997. 'Sense, Meaning, and Perception in Three Dance Cultures.' In J.C. Desmond (ed.) Meaning in Motion: New Cultural Studies of Dance. Durham, North Carolina: Duke University Press. pp. 269-87.

------. 2001. 'Looking at Movement as Culture: Contact Improvisation to Disco.' In A. Dils and A. Cooper Albright (eds.) Moving History / Dancing Cultures: A Dance History Reader. Middletown, Connecticut: Wesleyan University Press. pp. 404-13.

Bull, Deborah. 2002. The Dancer's Body. BBC. Transcribed to URL: 
www.bbc.co.uk/music/dancersbody, visited 25 May 2005.

Chau, Adam. 2006. Miraculous Response: Doing Popular Religion in Contemporary China. Stanford, California: Stanford University Press. 336 pp.

Classen, Constance. 1993. Worlds of Sense: Exploring the Senses in History and Across Cultures. London: Routledge. $172 \mathrm{pp}$.

Csordas, Thomas. 1993. 'Somatic Modes of Attention.' Cultural Anthropology 8(2): 135-56.

Downey, Greg. 2005. 'Educating the Eyes: Biocultural Anthropology and Physical Education.' Anthropology in Action 12(2): 56-71.

Farnell, Brenda. 1999. 'Moving Bodies, Acting Selves.' Annual Review of Anthropology 28: 341-73.

Foster, Susan Leigh. 1997. 'Dancing Bodies.' In J.C. Desmond (ed.) Meaning in Motion: New Cultural Studies of Dance. Durham, North Carolina: Duke University Press. pp. 235-57.

Friedson, Steven. 1996. Dancing Prophets: Musical Experience in Tumbuka Healing. Chicago: University of Chicago Press. 260 pp.

Geurts, Kathryn Linn. 2002. Culture and the Senses: Bodily Ways of Knowing in an African Community. Berkeley: University of California Press. 293 pp.

------. 2005. 'Consciousness as 'Feeling in the Body': A West African Theory of Embodiment, Emotion, and the Making of a Mind.' In D. Howes (ed) Empire of the Senses. Oxford: Berg. pp. 164-78.

Husserl, Edmund. 1960. Cartesian Meditation: An Introduction to Phenomenology. Trans. Dorion Cairns. The Hague: Martinus Nijoff. 157 pp.

Howes, David (ed). 1991. The Varieties of Sensory Experience: A Sourcebook in the Anthropology of the Senses. Toronto: University of Toronto Press. 336 pp.

Hsu, Elisabeth. 1999. The Transmission of Chinese Medicine. Cambridge: Cambridge University Press. 296 pp.

------. 2000. 'Towards a science of touch, part I: Chinese pulse diagnostics in early modern Europe.' Anthropology \& Medicine 7(2): 251-67.

Ingold, Tim. 2000. The Perception of the Environment: Essays on Livelihood, Dwelling, and Skill. London: Routledge. 465 pp.

2001. 'From the Transmission of Representations to the Education of Attention.' In H. Whitehouse (ed.) The Debated Mind: Evolutionary Psychology versus Ethnography. Oxford: Berg. pp. 113-53. 
Laban, Rudolf \& F. C. Lawrence. 1974. Effort: Economy of Human Movement, 2nd edition. London: MacDonald and Evans. 98 pp.

Lave, Jean \& Etienne Wenger. 1995. Situated Learning. Cambridge: Cambridge University Press. 138 pp.

Leder, Drew. 1990. The Absent Body. Chicago: University of Chicago Press. 218 pp.

Luria, Alexander R. 1970. 'The functional organization of the brain.' Scientific American 222(3): 66-78.

Mazis, Glen A. 1979. 'Touch and Vision: Rethinking with Merleau-Ponty Sartre on the Caress.' Philosophy Today 23(4): 321-8.

McLuhan, Marshall. 1962. The Gutenburg Galaxy: the Making of Typographic Man. Toronto: University of Toronto Press. 293 pp.

Merleau-Ponty, Maurice. 1962[1945]. Phenomenology of Perception. Trans. Colin Smith. London: Routledge and Kegan Paul. 446 pp.

Milton, Kay \& Maruška Svašek (eds). 2005. Mixed Emotions: Anthropological Studies of Feeling. Oxford: Berg. 232 pp.

Ness, Sally Ann. 1992. Body, Movement, and Culture: Kinesthetic and Visual Symbolism in a Philippine Community. Philadelphia: University of Pennsylvania Press. 292 pp.

Novack, Cynthia (a.k.a. Cynthia Jean Cohen Bull). 1990. Sharing the Dance: Contact Improvisation and American Culture. Madison, Wisconsin: University of Wisconsin Press. 258 pp.

Ong, Walter. 1969. 'The Shifting Sensorium.' In D. Howes (ed.) 1991, The Varieties of Sensory Experience: A Sourcebook in the Anthropology of the Senses. Toronto: University of Toronto Press. pp. 25-30.

Parviainen, Jaana. 2002. 'Bodily Knowledge: Epistemological Reflections on Dance.' Dance Research Journal 34(1): 11-26.

Potter, Caroline M.P. 2007. Learning to Dance: Sensory Experience in British Contemporary Dance Training. D.Phil thesis: University of Oxford. 292 pp.

Reed, Susan. 1998. 'The Politics and Poetics of Dance.' Annual Review of Anthropology 27: 503-32.

Sklar, Deidre. 2000. 'Reprise: On Dance Ethnography'. Dance Research Journal 32(1): 70-7.

Sherrington, Sir Charles S. 1947 [1906]. The Integrative Action of the Nervous System, $2^{\text {nd }}$ edition. Cambridge: Cambridge University Press. [first published New York: Scribner.] 433 pp. 
Skinner, Jonathan. 2005. 'Embodiment and Teaching and Learning in Anthropology.' Anthropology in Action 12(2): v-ix.

Stoller, Paul. 1989. The Taste of Ethnographic Things: the Senses in Anthropology. Philadelphia: University of Pennsylvania Press. 182 pp.

Wikan, Unni. 1990. Managing Turbulent Hearts: a Balinese Formula for Living. Chicago: The University of Chicago Press. 343 pp.

\footnotetext{
${ }^{\text {i }}$ Although the School is considered British, students stem from a wide range of nationalities, mostly European. Among thirty one-year students with whom I had the closest contact, British students (all English) were the most numerous, but at nine but did not constitute a majority. The rest of the group consisted of five Italians, five Spanish, two Germans, one Turkish/German, two French, two Taiwanese, one American, one Czech, one Japanese, and one South African.

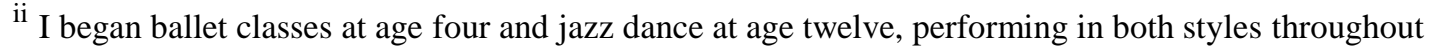
school and university. For two years starting at the age of twenty-one, I danced for a semi-professional West African drumming and dance ensemble that specialized in dances taught by local residents of Conakry, Guinea, to international musicians and dancers. Within the UK, I undertook three years of intensive study in ballroom dance, Latin American dance, and classical ballet, performing lead roles such as Aurora in The Sleeping Beauty. Prior to fieldwork, I had not undertaken any full-time professional dance training.

iii With its associations of mechanical reflex actions, the term 'proprioception' is rarely used in the studio; during fieldwork I heard it just once, in an anatomy lecture about stretching. In this context 'proprioceptors' (i.e. stretch receptors embedded in muscular tissue and Golgi tendon apparati near to where muscle connects to bone) were described as part of a biological feedback system of information exchange between peripheral muscles and the central neurological organs that governed their movement (Blakey 1994).

iv This definition of proprioception was used in the BBC series "The Dancer's Body", which was hosted and later transcribed by former Royal Ballet member Deborah Bull.

${ }^{\mathrm{v}}$ Sherrington hints at this understanding of a sense of motion when he writes, "Evidently the greater part of the skeletal musculature is all the time steadily active, antagonizing gravity in maintaining the head raised, the trunk semi-erect, and the hind-legs tautly flexed.” (1947[1960]: 339).

${ }^{\mathrm{vi}}$ Although both men and women trained at the School, women were in the majority, and among the thirty one-year students with whom I worked most closely only two were men. I have therefore opted to use the feminine pronoun when referring generally to a student at the School.
} 